\title{
Emphysematous Gastritis
}

Afsana Asharaf, MD; Parth Desai, DO; Maryam Sanati, MD

From the Department of Internal Medicine at John H. Stroger, Jr. Hospital of Cook County in Chicago, IL.

Financial Disclosures: None reported.

Support: None reported.

Address correspondence to

Parth Desai, DO, John

H. Stroger, Jr. Hospital of Cook

County, 1969 Ogden Ave,

Chicago, IL 60612.

Email:

parth.desai@cookcountyhhs.

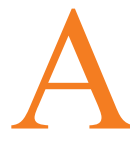

58-year-old man presented an acute onset of diffuse abdominal pain and melena 1 day after he ingested a plastic foreign body. He was afebrile and hemodynamically stable with a distended tender abdomen and absent bowel sounds. Laboratory findings demonstrated leukocytosis (white blood cell count, 13,200 $\mathrm{mm}^{3}$ ). An abdominal computed tomography (CT) scan without contrast showed air within the gastric wall (image, red arrows), and treatment for emphysematous gastritis was initiated. Management consisted of nothing by mouth orders, total parenteral nutrition, intravenous pantoprazole, and broad-spectrum intravenous piperacillin-tazobactam for 10 days. The patient was discharged in stable condition.

Fewer than 200 cases of emphysematous gastritis have been described in the literature. It is characterized by the presence of air in the gastric wall, secondary to a bacterial infection, and has been associated with a mortality rate of up to $60 \%{ }^{1}$
It is important to distinguish this entity from gastric emphysema, which is a benign radiologic finding. ${ }^{3}$ Imaging with CT is the diagnostic investigation of choice, and conservative management is the mainstay of therapy, with early initiation of broad-spectrum antibiotics. In the acute setting, the role for surgery has not been well defined and is often reserved for patients who deteriorate despite optimal medical management or when there is evidence of infarction or perforation. ${ }^{1}$ (doi:10.7556/jaoa.2019.140)

\section{References}

1. Nemakayala DR, Rai MP, Rayamajhi S, Jafri S-M. Role of conservative management in emphysematous gastritis. Case Rep. 2018;2018:bcr-2017-222118.

2. Moosvi, AR, Saravolatz LD, Wong DH, Simms SM. Emphysematous gastritis: case report and review. Clin Infect Dis. 12(5);1990:848-855. doi:10.1093/clinids/12.5.848

3. Sharma A, Mukewar S, Chari ST, Wong Kee Song LM. Clinical features and outcomes of gastric ischemia. Dig Dis Sci. 2017;62 (12):3550-3556. doi:10.1007/s10620-4807-4

() 2019 American Osteopathic Association

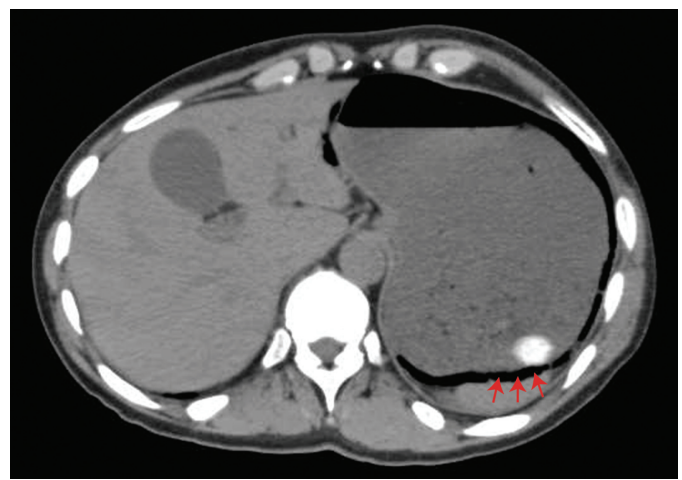

